\title{
Production of high quality coatings on light alloys using Plasma Electrolytic Oxidation (PEO)
}

\author{
R. O. Hussein ${ }^{1}$, X. Nie $^{2}$ \& D. O. Northwood ${ }^{2}$ \\ ${ }^{1}$ Faculty of Engineering, Technology and Science, \\ Higher Colleges of Technology, Al Ain, UAE \\ ${ }^{2}$ Department of Mechanical, Automotive and Materials Engineering, \\ University of Windsor, Canada
}

\begin{abstract}
Plasma Electrolytic Oxidation (PEO) is a high voltage plasma-assisted oxidation process which involves the creation of plasma discharges around a metal surface component immersed in an environmentally-friendly aqueous electrolyte to form ceramic oxide coatings which can, if correctly formed, impart a high corrosion and wear resistance. During PEO coating, there are three simultaneous processes taking place, namely the electrochemical reactions, the plasma chemical reactions and thermal oxygen diffusion. All PEO-coatings have a three-layer structure with a porous outer layer, and intermediate dense layer and a thin inner dense layer. It is through control of the relative amounts (thickness) and composition of these three that high quality coatings can be obtained. In this paper we describe how processing parameters including current density, current mode (unipolar, bipolar, hybrid), and electrolyte (concentration and composition) effect the quality of the coatings as measured by the corrosion and wear resistance. In general terms, an intermediate current density and a bipolar current mode lead to the most compact and high quality coatings, although the growth rate is reduced compared to using a unipolar current mode and higher current densities. The growth rate can be increased by increasing the electrolyte concentration. Incorporation of silicates and aluminates into the electrolyte can result in the formation of hard spinels in the coatings, which can then lead to better wear and corrosion resistance.

Keywords: PEO coatings, coating mechanism, process parameters, corrosion, wear.
\end{abstract}




\section{Introduction}

Current coating schemes are complex, multilayer systems that incorporate many different technologies and must be conducted very carefully in order to adequately protect lightweight metals and their alloys from wear and corrosion in harsh service conditions. In order to achieve higher levels of protection, one of the most promising coating methods is the PEO technique. Plasma Electrolytic Oxidation (PEO) is a high voltage plasma-assisted oxidation process, considered as one of the most cost-effective and environmentally friendly ways to form a thick, ultrahard and adherent ceramic oxide by plasma discharge of lightweight metals $(\mathrm{Mg}$, $\mathrm{Al}$ and $\mathrm{Ti}$ ) and their alloys $[1,2]$. The PEO process involves the creation of plasma discharges around a metal component immersed in an alkaline electrolyte when a high potential is applied to it. During the PEO process, different types of discharges will take place [3, 4]. An important consequence of the occurrence of those discharges is the development of metallurgical processes in the growing oxide layer, which are induced by the heat liberated in discharge channels from electron avalanches. Because of the local high temperature and the strong electric field, molten oxide is ejected from the coating/substrate interface into the coating surface where it is rapidly solidified and re-crystallized by the electrolyte. Hence, the formation mechanisms for the coatings are complex due to the involvement of the electrochemical reactions, the plasma chemical reactions and thermal oxygen diffusion.

In general, PEO coatings on lightweight alloys have been found to have a threelayered structure as shown in Figure 1. Figure 1(a) is a SEM micrograph of a crosssection of a coated $\mathrm{Al}$ alloy. Figure 1(b) is a schematic diagram showing a porous outer layer, an intermediate layer that is relatively dense, and a thin inner dense (barrier) layer that is well adhered to the substrate. Although it is the intermediate dense layer that can provide good mechanical properties (eg wear) and corrosion protection, it is the inner dense layer that ultimately provides the best corrosion performance [5-9].

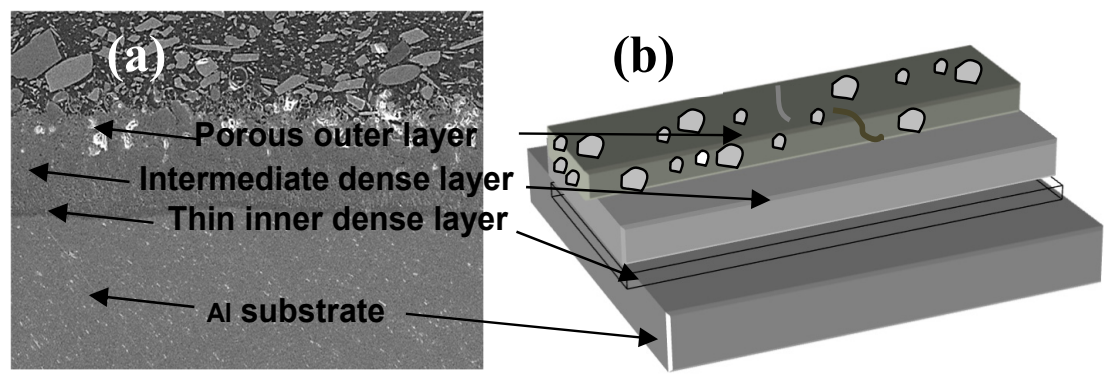

Figure 1: PEO coating on Al alloy showing (a) SEM micrograph of crosssection. (b) Schematic diagram of layer structure $[5,9]$.

Many processing parameters can affect the PEO process, including electrolyte concentration and composition [10], substrate material [11], and electrical 
parameters, mainly current mode and current density [8, 12]. Different current modes have been utilized in the PEO treatment including, DC, AC, unipolar, bipolar and hybrid (combination of bipolar and unipolar) current modes [13] which play important roles in the consequent voltage breakdown and discharge events, both in terms of discharge intensity and density, local melting and oxidation of the substrate, quenching and re-crystallization processes. The discharges have a profound effect on the coating microstructure, thickness, roughness, porosity, hardness, and coating growth rate, and hence affect the corrosion and wear resistance of the coated lightweight alloy.

PEO has been used to rapidly and economically produce oxide coatings on lightweight alloy components of almost any shape and size. There are various problems to be solved but there is a much bigger potential for PEO in automotive and other applications than currently used $[6,9]$. Although a general picture of the PEO coating growth mechanisms [14, 15], discharge behaviour [3, 15] and resulting coating formation has been developed, a number of gaps in knowledge remain concerning processing-structure-properties-performance relationships. Further work was required in order to specify the critical parameters that would lead to more reproducible and higher performance coatings. In this paper we examine the interactive effects of PEO processing parameters, and alloy composition and microstructure, on the microstructure of the coatings and, therefore, on the resulting corrosion and tribological properties. To accomplish this, we mainly use examples from our own work on Mg-alloys, although many of the principles are equally applicable to the other light alloys based on aluminum $[9,16,17]$ or titanium $[8,18]$.

\section{PEO-coating mechanisms}

The growth of the PEO oxide coating mainly occurs due to three different, yet simultaneous, processes, namely: the electrochemical reactions [1], the plasma chemical reactions [19] and thermal diffusion [20]. Fig. 2 is a schematic of the PEO coating growth process on a magnesium alloy substrate. The main electrochemical reactions occur at the coating/electrolyte interface, through different mechanisms depending on the electrolyte. According to the study by Yerokhin et al. [21], oxide layer formation is induced both by the ionic component of the current, which is transmitted via surface discharges, and by the anodizing current passing across the surface, which is free of discharges.

The plasma chemistry of the surface discharges involves, on one hand, charge transfer at the substrate/electrolyte interface, and on the other hand, strong ionization and charge transfer effects between the substrate surface and the electrolyte through the oxide layer with the aid of the plasma. During the PEO process different types of discharges will take place [5]. An important consequence of the occurrence of those discharges is the development of metallurgical processes in the growing oxide layer, which are induced by the heat liberated in discharge channels from electron avalanches. The ceramic coating grows inwards to the alloy substrate (inner layer) and outwards to the coating surface (outer layer) simultaneously [15]. 


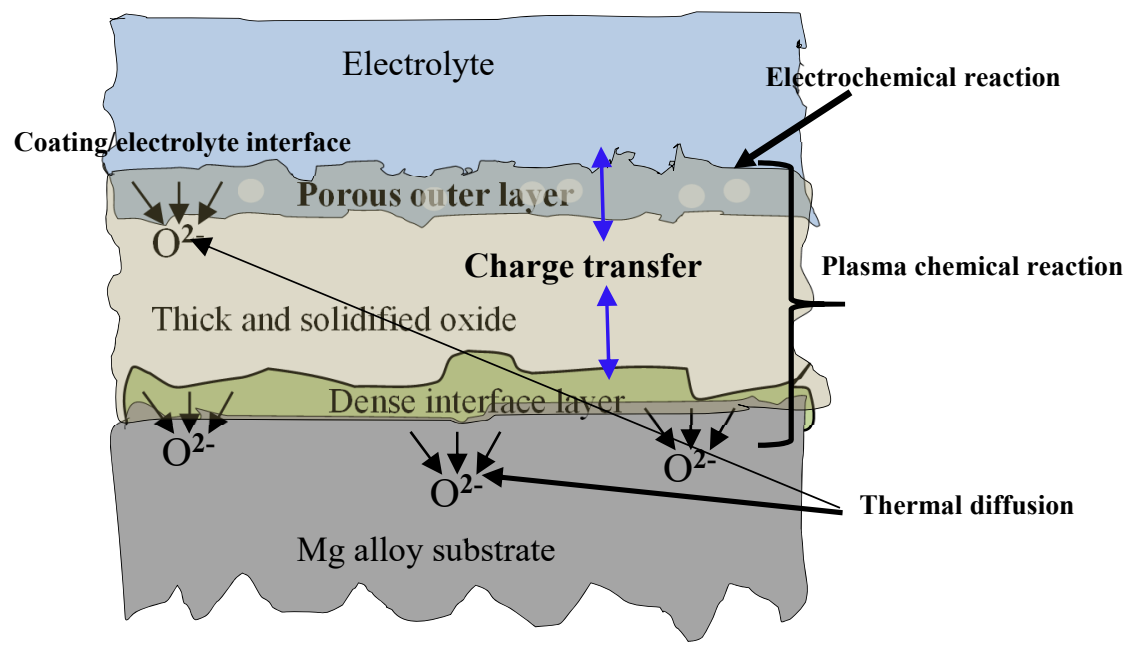

Figure 2: Schematic of a PEO coating growth process on a Mg-alloy substrate.

Both thermally-activated diffusion and anion transfer have an important contribution to coating growth [22]. Inward oxygen diffusion into the alloy substrate plays a key role in coating growth. The growth rate is influenced by the plasma temperature, which enhances the rate of oxygen transport towards the magnesium substrate as shown in Fig. 2. Hence, the rates of growth of the outer and inner oxide layers results from a combination of three processes namely, (i) discharge processes causing the substrate to melt and oxidize when flowing out through the discharge channels and being rapidly cooled at the surface-electrolyte interface, (ii) partial destruction of the outer layer due to strong discharges and (iii) diffusion of oxygen process from the electrolyte towards the substrate through the coating.

\section{Plasma discharge effects on microstructure of coating and properties}

Quantitative studies have been performed by our group relating processing to performance $[6,13,15,16,22,23]$. It has been confirmed that a PEO processing of $\mathrm{Mg}$ alloys is strongly influenced by such parameters as electrolyte chemistry, current mode and density and substrate alloy. The effects of these PEO process parameters on the coating quality and properties are discussed in more detail in sections 3.1 to 3.3 .

\subsection{Current mode and current density effects}

With the aim of improving the characteristics of the PEO coatings, many attempts $[4,5,20]$ have been made to improve the supplied current regimes, suggesting different forms and duration of the current pulses. Four different current modes (unipolar, bipolar and hybrid (unipolar-bipolar and bipolar-unipolar)) were used in the PEO processing of Mg-alloy AM60B in a mixed aluminate and phosphate electrolyte $[22,24]$. Changing the current mode produces changes in the PEO 
process characteristics, including the breakdown voltage and discharge events, both in terms of discharge intensity and density [22]. Increasing the current density and/or voltage led to an increase in layer thickness, as well as enlargement of the surface craters.

Fig. 3 shows the SEM micrographs of the coating surfaces and coating crosssections on AM60B [22]: H11 treated using unipolar current mode only for 15 minutes, $\mathrm{H} 12$ by completing the treatment of $\mathrm{H} 11$ using bipolar current mode for another 15 minutes; $\mathrm{H} 21$ treated firstly using bipolar current mode; H22 completed the treatment using unipolar mode for second 15 minutes. Controlling or reducing the strong discharges (by bipolar current mode, appropriately controlling the ratio of the positive to negative pulse currents as well as their timing) had a significant positive effect on the plasma temperature profiles and leads to denser inner layer microstructures with less porosity. The order of the combined current modes is essential. Hybridl case improves the coating quality compared to other cases as the bipolar mode acts to repair the damage caused by the unipolar mode.

The role played by current density using bipolar current modes on the microstructural characteristics of oxide coatings produced on a AZ91D Mg alloy in an electrolyte of $8 \mathrm{~g} / 1 \mathrm{Na} 2 \mathrm{~A} 12 \mathrm{O} 4 \mathrm{and} 1 \mathrm{~g} / \mathrm{K} \mathrm{KOH}$ was also investigated using the process parameters given in Table 1 [23]. Although increasing the cathodic current density from $0.05 \mathrm{~A} / \mathrm{cm}^{2}$ to $0.11 \mathrm{~A} / \mathrm{cm}^{2}$ produced a thicker coating (thickness increased from $22 \mu \mathrm{m}$ to $60 \mu \mathrm{m}$ ), there was a corresponding increase in coating defects, including porosity and microcracks.

Corrosion testing of the coated samples was conducted using EIS and results are shown in Fig. 4.

All PEO coatings offered significant corrosion protection to the AZ91D alloy. The Bode impedance diagram (Fig. 4(b)) shows the impedance modulus in the LF range, varies from $10^{5.5} \Omega \mathrm{cm}^{2}$ to $10^{6.5} \Omega \mathrm{cm}^{2}$ for $\mathrm{S} 1$ and $\mathrm{S} 2$ but is much lower $\left(10^{3.1}\right.$ $\Omega \mathrm{cm}^{2}$ ) for S3 which is coated at a high current density [23]. Compared to uncoated alloy, the high impedance and high polarization resistance values in the EIS results demonstrated that the PEO coating did not undergo any significant degradation and that the coating at the metal-substrate interface was providing significant protection. It is concluded that the corrosion protection performance of the PEO coatings is indirectly dependent on the current density and is controlled by the amount of porosity and other coating defects which could control the penetration rate of the electrolyte through the PEO coating [23].

Similar effects of current mode have been found for aluminium alloys. Fig. 5 shows the cross sections of an AA5052 Al alloy coated using either unipolar (Al 1) or bipolar current modes ( $\mathrm{Al} 2$ coated for $60 \mathrm{~min}$ and $\mathrm{Al} 3$ coated for $90 \mathrm{~min}$ respectively) [17]. Al 1, coated using the unipolar current mode, shows a significant amount of connected porosity, holes and other structure defects within the coating and near the coating/substrate interface, Fig 5(a). The cross-sections of samples Al 2 and Al 3 shown in Figs 5(b) and (c) which were obtained using pulsed bipolar current mode with different treatment times, show that the surface/coating interface was smooth and almost free from porosity and defects. Compared to the sample $\mathrm{Al} 2$, the sample Al 3 showed a thicker coating with relatively less porosity in the inner layer. 
(i)

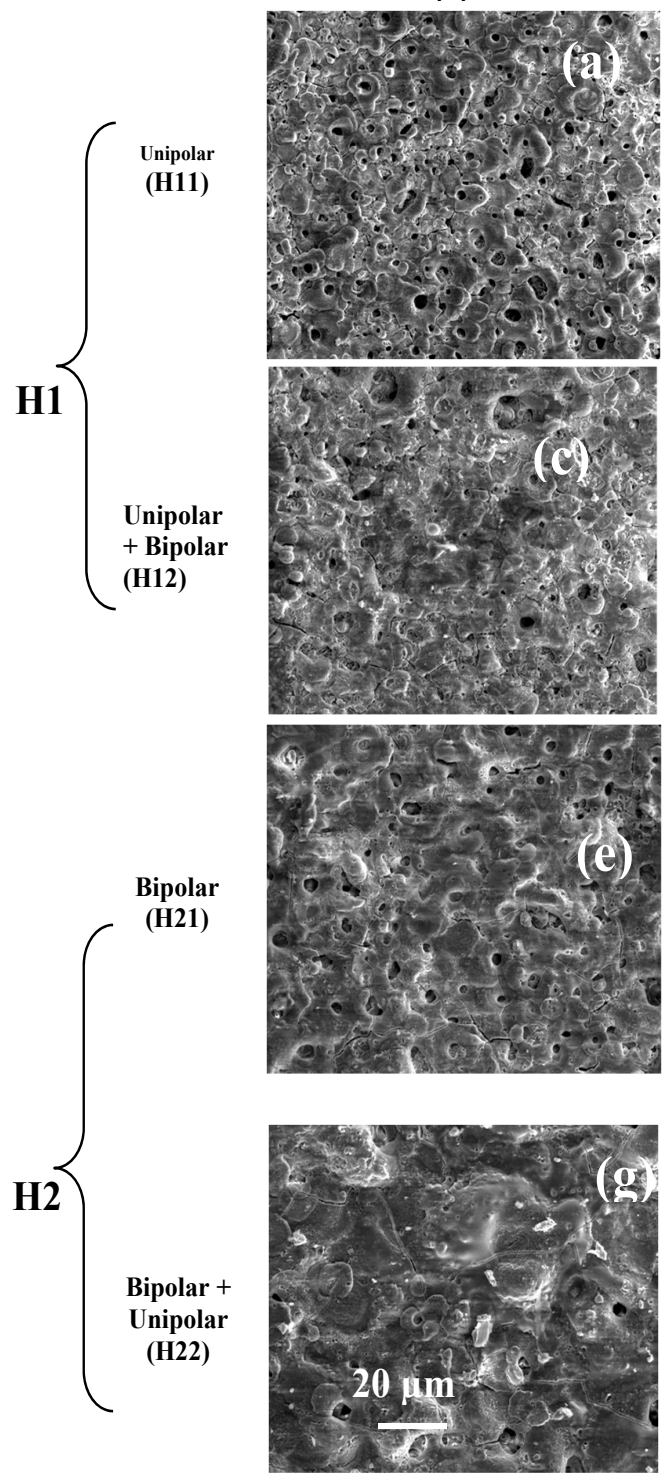

(ii)
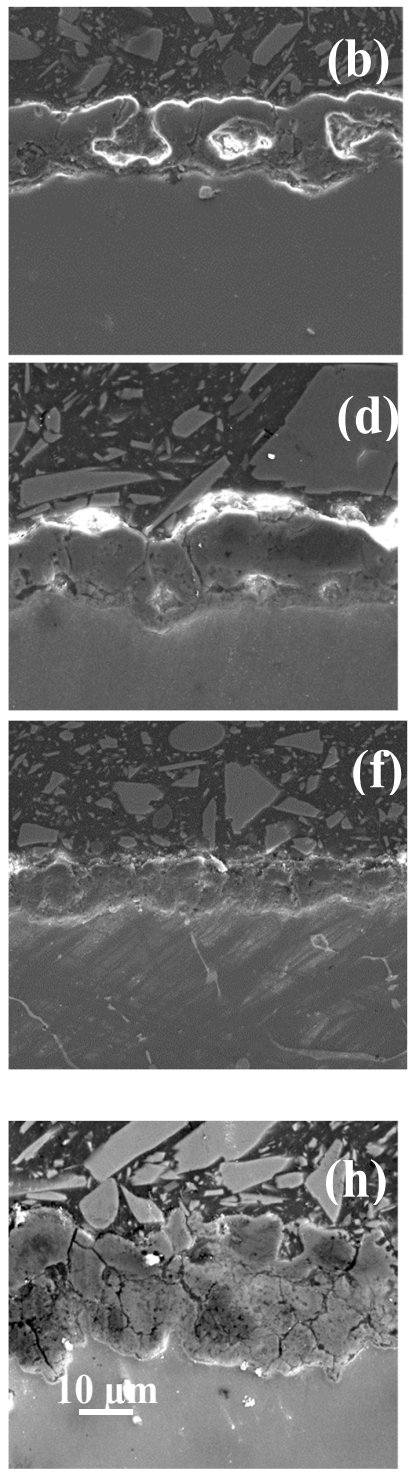

Figure 3: (i) Morphology of oxide coatings on Mg AM60B magnesium alloy using secondary electron mode (SE) (ii) SEM micrographs of polished sections of coatings using secondary electron mode (SE) and for: (a), (b) unipolar H11, (c, d) hybrid1 (uni + bipolar), (e), (f) bipolar $\mathrm{H} 21$ and $(\mathrm{g})$, (h) hybrid2 (bi + unipolar) current modes [22]. 
Table 1: $\quad$ PEO process parameters for coating AZ91D Mg alloy [23].

\begin{tabular}{|c|c|c|c|c|c|}
\hline S & Current mode & Time $(\min )$ & $\mathrm{I}^{+}(\mathrm{A})$ & $\mathrm{J}^{+}\left(\mathrm{A} / \mathrm{cm}^{2}\right)$ & $\mathrm{I}^{-}(\mathrm{A})$ \\
\hline S1 & Bipolar & 30 & 0.68 & 0.05 & 0.5 \\
\hline S2 & Bipolar & 30 & 0.95 & 0.07 & 0.7 \\
\hline S3 & Bipolar & 30 & 1.5 & 0.11 & 1.1 \\
\hline
\end{tabular}
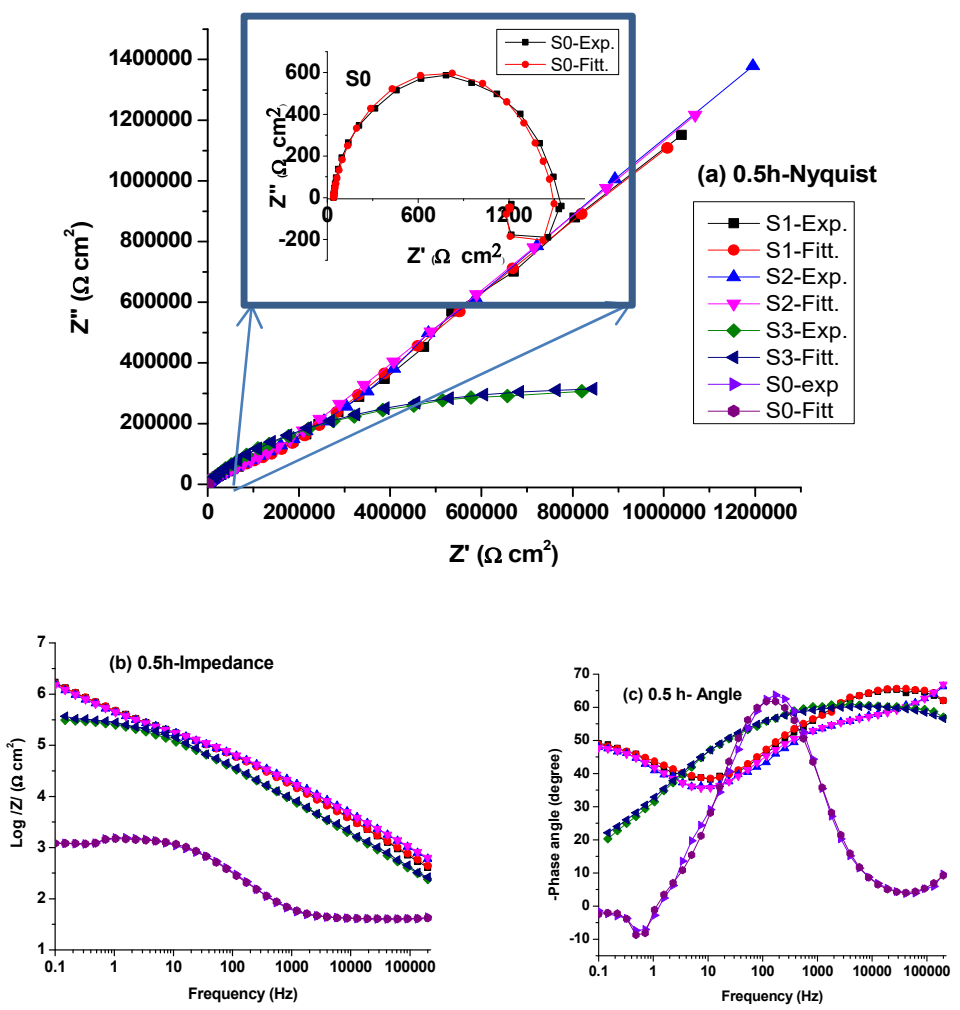

Figure 4: EIS plots of coated (S1-S3) and uncoated (S0) AZ91D Mg alloy at different current densities for $0.5 \mathrm{~h}$ immersion time ((a) Nyquist, (b) Impedance and (c) angles plots) [23].

The potentiodynamic polarization curves of the uncoated AA5052 Al alloy (Al 0 ) and the PEO coated specimens using either unipolar (Al 1) or bipolar current modes (Al 2 and Al 3), Fig. 6, clearly show the enhanced corrosion resistance afforded by the coatings. In contrast to the uncoated AA 5052, all PEO coated samples had more positive corrosion potentials and lower corrosion current densities. By using bipolar current mode the corrosion resistance increased from $31 \mathrm{M} \Omega / \mathrm{cm}^{2}$ for the uncoated alloy to $2631 \mathrm{M} \Omega / \mathrm{cm}^{2}$ [9]. 

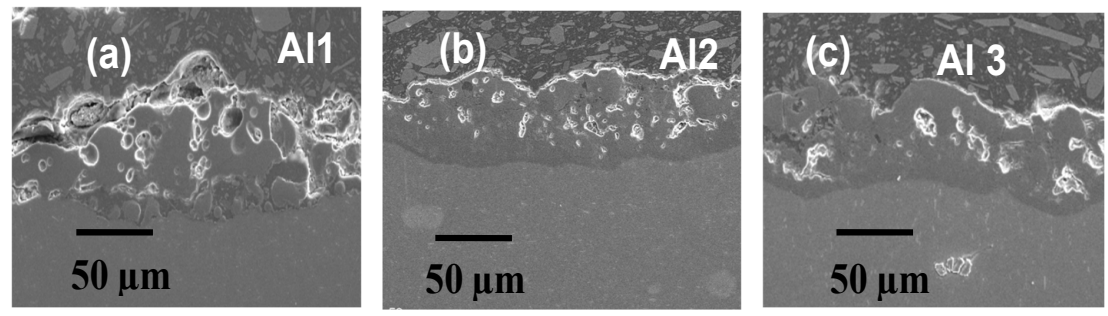

Figure 5: SEM micrographs of cross-section morphology of oxide coatings on Al AA5052 alloy for: (a) unipolar Al1, (b), (c) bipolar Al2 and Al3 coated for $60 \mathrm{~min}$ and $90 \mathrm{~min}$ respectively [17].

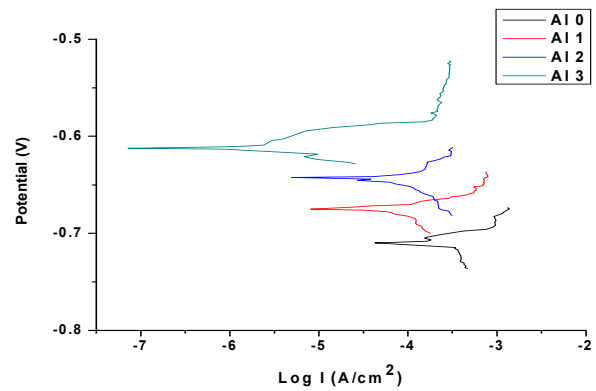

Figure 6: Potentiodynamic polarization curves in $3.5 \% \mathrm{NaCl}$ solution of the uncoated (A10) and coated $5052 \mathrm{Al}$ alloy samples using unipolar (A11) and bipolar (A12-A13) current modes [9].

The last example will explain the role played by current modes on the microstructural and tribological characteristics of oxide coatings produced on a AM60B $\mathrm{Mg}$ alloy in a $7 \mathrm{~g} / 1 \mathrm{~K}_{4} \mathrm{P}_{2} \mathrm{O}_{7}+3 \mathrm{~g} / 1 \mathrm{Na}_{2} \mathrm{Al}_{2} \mathrm{O}_{4}$ and $1 \mathrm{~g} / \mathrm{l} \mathrm{KOH}$ electrolyte [24]. A unipolar current mode gives rise to thicker $(\approx 48 \mu \mathrm{m})$, more porous (amount and size) coatings with a higher surface roughness than those produced using a bipolar current mode $(\approx 37 \mu \mathrm{m})$ or $\mathrm{H} 1(\mathrm{U}+\mathrm{B})$ and $\mathrm{H} 2(\mathrm{~B}+\mathrm{U})$ modes $(\approx 30 \mu \mathrm{m})$ [24]. As shown in Fig. 7, the denser coatings with lower surface roughness that are produced by the $\mathrm{B}$ and $\mathrm{H} 1$ current modes compared to the $\mathrm{U}$ and $\mathrm{H} 2$ modes lead to improved tribological performance in both pin-on-disk (Fig. 7(b), and inclined impact-sliding tests.

\subsection{Alloy composition effects}

The effect of substrate composition on the PEO coatings microstructure and properties for pure magnesium and magnesium alloys AM60B ( $\mathrm{Mg}-6 \mathrm{Al}-$ $0.2 \mathrm{Zn}), \mathrm{AJ} 62(\mathrm{Mg}-6 \mathrm{Al}-2 \mathrm{Sr})$ and AZ91D(Mg - 9Al $-1 \mathrm{Zn})$ was investigated [25]. The variation of the average total coating thickness with PEO treatment time is shown in Fig. 8. The coating thickness increases linearly with coating time which is in good agreement with most other PEO experiments [26]. For the bipolar current mode, the average growth rate was $0.9 \pm 0.05 \mu \mathrm{m} / \mathrm{min}$. However, AZ91D 

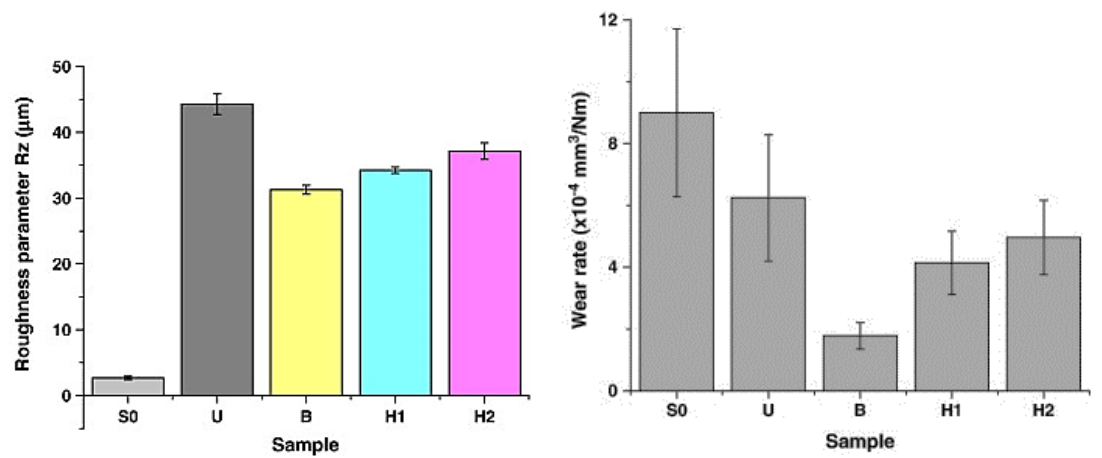

Figure 7: (a) Roughness parameter Rz and (b) Wear rates of the oxide coatings formed using different current modes and the uncoated $\mathrm{Mg}$ alloy substrate [24].

$\mathrm{Mg}$ alloy shows a relatively higher coating thickness compared with other samples.

Each coating has a different phase composition and surface morphology due to the effect of the different alloying elements. Electrochemical impedance spectroscopy (EIS) corrosion testing showed that the bipolar PEO coated AZ91D $\mathrm{Mg}$ alloy had a higher corrosion resistance when compared to coated AM60B, AJ62 and pure Mg. The ranking for corrosion resistance in $3.5 \% \mathrm{NaCl}$ was $\mathrm{Mg}$ uncoated < coated pure Mg < coated AJ62< coated AM60B < coated AZ91D which is consistent with the average coating thickness results.

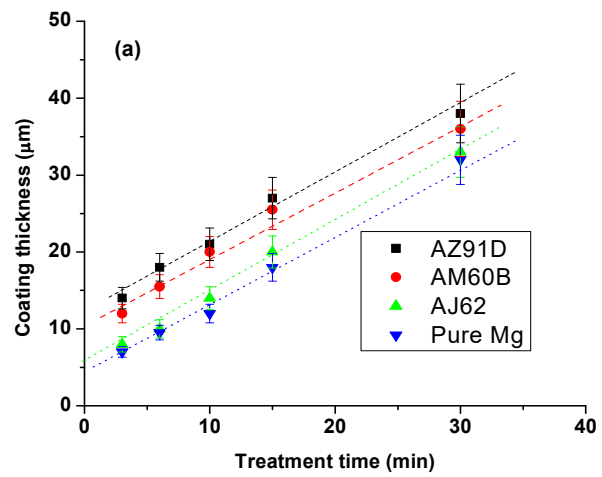

Figure 8: Average coating thickness variation with PEO processing time for different $\mathrm{Mg}$ alloys [25].

\subsection{Electrolyte concentration and composition effects}

PEO coatings on $\mathrm{Mg}$ alloys and other lightweight alloys are normally produced using environmentally friendly base electrolytes $(\mathrm{NaOH} / \mathrm{KOH})$ with the addition of silicate, aluminate, phosphate or polyphosphate-containing alkaline electrolytes to increase the conductivity of the electrolyte solution. To illustrate the effects of electrolyte composition and concentration on the coating quality, we will use our 
Table 2: $\quad$ Electrolyte composition for PEO processing of AZ91D.

\begin{tabular}{|c|c|c|c|}
\hline Sample & $\mathrm{KOH}(\mathrm{g} / \mathrm{l})$ & $\mathrm{Na}_{2} \mathrm{Al}_{2} \mathrm{O}_{4}(\mathrm{~g} / \mathrm{l})$ & $\mathrm{Na}_{2} \mathrm{WO}_{4} .2 \mathrm{H}_{2} \mathrm{O}(\mathrm{g} / \mathrm{l})$ \\
\hline $\mathrm{S} 1$ & 2 & 8 & 0.0 \\
\hline $\mathrm{S} 2$ & 2 & 8 & 1.0 \\
\hline $\mathrm{S} 3$ & 2 & 8 & 2.0 \\
\hline $\mathrm{S} 4$ & 2 & 8 & 6.0 \\
\hline S5 & 2 & 15 & 0.0 \\
\hline
\end{tabular}

work on an AZ91D magnesium alloy which was PEO-coated using a base $\mathrm{KOH}$ electrolyte with additions of aluminate $\left(\mathrm{Na}_{2} \mathrm{Al}_{2} \mathrm{O}_{4}\right)$ and tungstate $\left(\mathrm{Na}_{2} \mathrm{WO}_{4}\right)$ as detailed in Table 2 [27].

Table 3 provides a summary of the breakdown voltage at which sparking occurs, coating thickness, colour and composition (at surface). With increasing electrolyte concentration, the breakdown voltage is decreased and a thicker coating is produced. Increasing aluminate concentration led to a higher aluminium content in the coating and a higher tungstate addition led to a higher tungsten concentration in the coating.

Table 3: Breakdown voltage and time, thickness, color and composition of coating.

\begin{tabular}{|c|c|c|c|c|c|c|c|c|}
\hline \multirow[t]{2}{*}{$\mathbf{S}$} & \multicolumn{2}{|c|}{ Breakdown } & \multirow{2}{*}{$\begin{array}{c}\text { Coating } \\
\text { thickness. } \\
(\mu \mathrm{m})\end{array}$} & \multirow[t]{2}{*}{ Color } & \multicolumn{4}{|c|}{ Composition (wt\%") } \\
\hline & $\mathrm{v}(\mathbf{V})$ & $t(\min )$ & & & $\mathbf{O}$ & Mg & Al & $\mathrm{W}$ \\
\hline S1 & 390 & 2.0 & $25 \pm 2.5$ & Gray & 37.3 & 33.3 & 29.1 & 0.0 \\
\hline S5 & 360 & 1.5 & $23 \pm 2.3$ & Gray & 38.3 & 26.9 & 34.7 & 0.0 \\
\hline $\mathbf{S 2}$ & 375 & 0.50 & $30.0 \pm 3$ & Gray/light green & 37.4 & 33.4 & 26.8 & 2.3 \\
\hline $\mathbf{S 3}$ & 360 & 0.40 & $29 \pm 2.9$ & Gray/medium green & 36.1 & 30.7 & 30.1 & 3.1 \\
\hline S4 & 280 & 0.25 & $43 \pm 4.5$ & Green with black spots & 35.2 & 29.4 & 26.9 & 8.6 \\
\hline
\end{tabular}

*As measured at the surface of the coatings using EDS.

XRD spectra of all PEO-coated samples are shown in Fig. 9(a). Detailed identification of the phases present for samples S1 and S4 are given in Fig. 9(b) and (c), respectively.

For S2, S3, S4 samples as well as $\mathrm{MgO}$, and an increased amount of $\mathrm{MgAl}_{2} \mathrm{O}_{4}$, the tungsten containing phases $\mathrm{WO}_{3}$ and $\mathrm{MgWO}_{4}$ are also present. The addition of 6g/l tungstate (S4), Fig. 9(c), causes the amorphous phases to disappear leaving the hard spinel $\mathrm{MgAl}_{2} \mathrm{O}_{4}$ phase, and creates the new phases, $\mathrm{WO}_{3}$ and $\mathrm{MgWO}_{4}$ which cause the greenish color with some black spots on the samples. The existence of $\mathrm{Na}_{2} \mathrm{WO}_{4} \cdot 2 \mathrm{H}_{2} \mathrm{O}$ in the electrolyte will cause some of the $\mathrm{WO}_{4}{ }^{2-}$ ions to lose the electrons forming the black $\mathrm{WO}_{3}$ compound. The main electrochemical reactions occurring during the $\mathrm{PEO}$ process in tungstate-containing electrolytes are as follows [27]:

$$
\begin{aligned}
& 2 \mathrm{WO}_{4}{ }^{2-}-4 \mathrm{e}^{-} \rightarrow 2 \mathrm{WO}_{3}+\mathrm{O}_{2} \uparrow \\
& \mathrm{WO}_{3}+3 \mathrm{Mg} \rightarrow 3 \mathrm{MgO}+\mathrm{W}
\end{aligned}
$$

Fig 9(d) shows that the tungsten was deposited all through the coating cross section. 

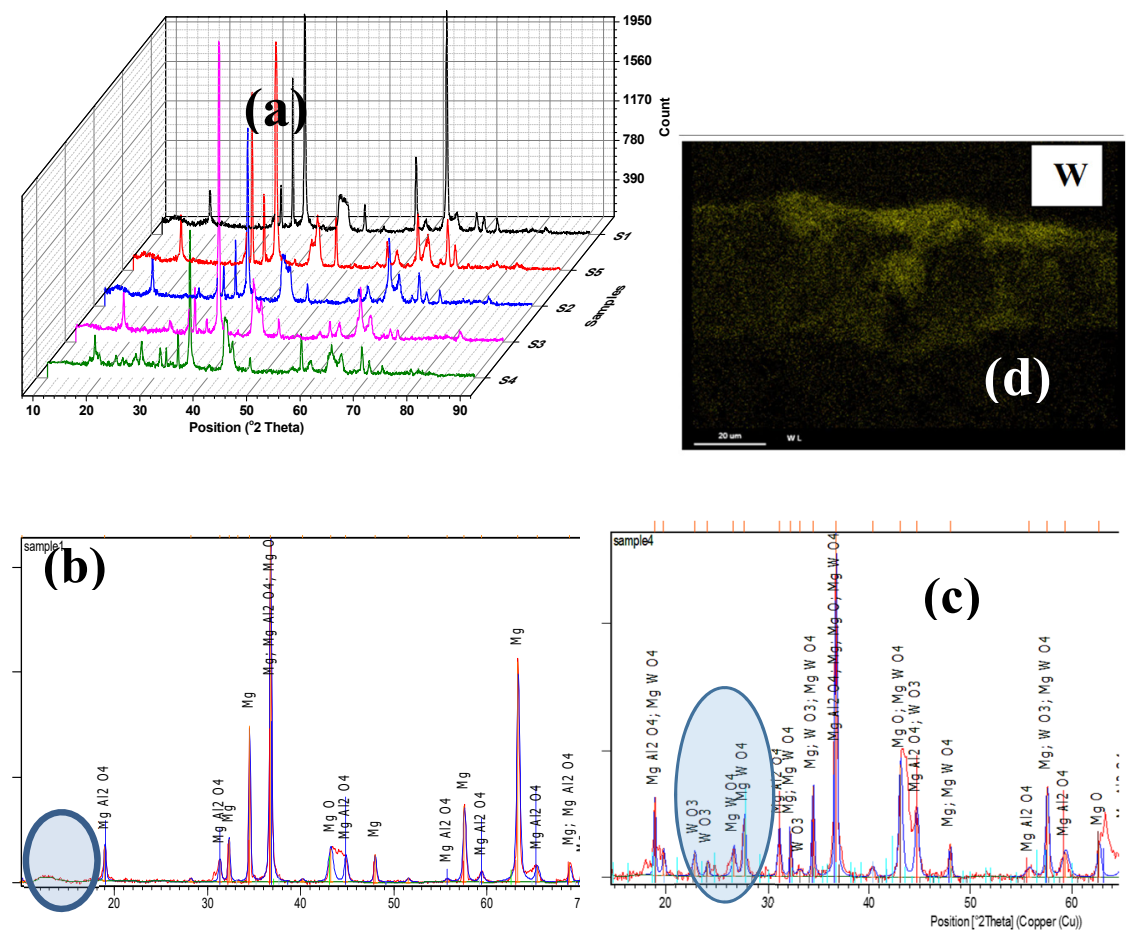

Figure 9: XRD patterns of oxide coatings formed in aluminate- $\mathrm{KOH}$ electrolyte with addition of different concentrations of $\mathrm{Na}_{2} \mathrm{W0}_{4}$ : (a) all samples (b) $0 \mathrm{~g} / 1 \mathrm{Na}_{2} \mathrm{WO}_{4}$, (c) $6.0 \mathrm{~g} / \mathrm{l} \mathrm{Na}_{2} \mathrm{WO}_{4}$ and (d) EDX tungsten (W) mapping of cross-sections of AZ91D Mg alloy PEO coated sample S4 [27].

Potentiodynamic polarization corrosion testing of all samples was conducted in $3.5 \% \mathrm{NaCl}$ and the results are shown in Figs 10(a), (b). Compared to the uncoated AZ91D, all PEO-coated samples exhibited a higher polarization resistance, a lower corrosion current density and a higher (more noble) corrosion potential than the uncoated alloy (S0). The electrolyte concentration and composition directly influences the surface morphology, coating microstructure, porosity level, thickness and phase composition of the coatings, which, in turn, affects the corrosion performance. Increasing the aluminate concentration in the electrolyte from 8 to $15 \mathrm{~g} / \mathrm{l}$, produces a coating that is denser and contains a higher amount of the spinel phase relative to $\mathrm{MgO}$. This produces a more corrosion resistant coating: see Fig. 10(a). The addition of tungstate to an electrolyte containing $8 \mathrm{~g} / \mathrm{l}$ aluminate increases the conductivity of the electrolyte, lowers the break-down potential, lowers the porosity/defect density of the coatings, increases the coating growth rate and produces a thicker substrate/coating interface layer, increases the $\mathrm{MgAl}_{2} \mathrm{O}_{4}$ spinel phase content, and leads to the formation of the tungstate-containing phases $\mathrm{WO}_{3}$ and $\mathrm{MgWO}_{4}$. All these factors lead to an improvement in corrosion resistance: see Fig. 10(b). 

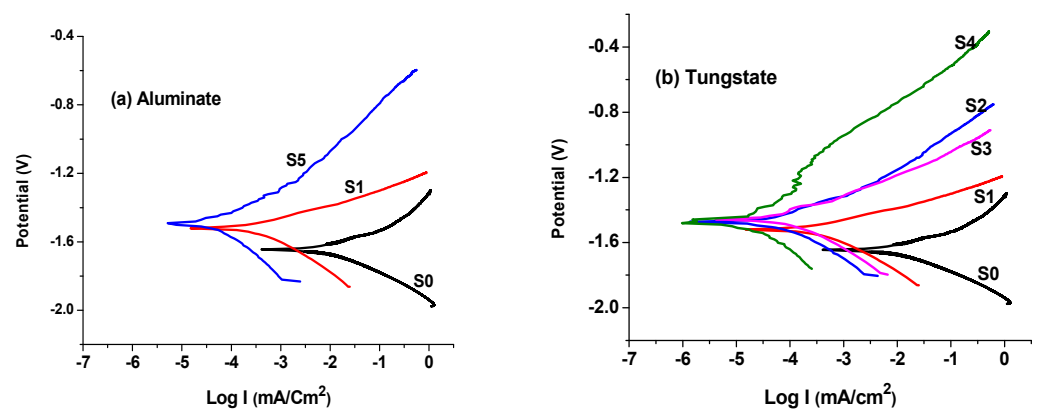

Figure 10: Potentiodynamic polarization curves of the uncoated (S0) and coated samples with (a) different aluminate concentrations (S1 and S5) and (b) different tungstate concentrations $(\mathrm{S} 1-\mathrm{S} 4)$, for $0.33 \mathrm{~h}$ immersion time [27].

\section{Relationships between processing parameters and performance}

A schematic describing these general relationships is given in Fig. 11.

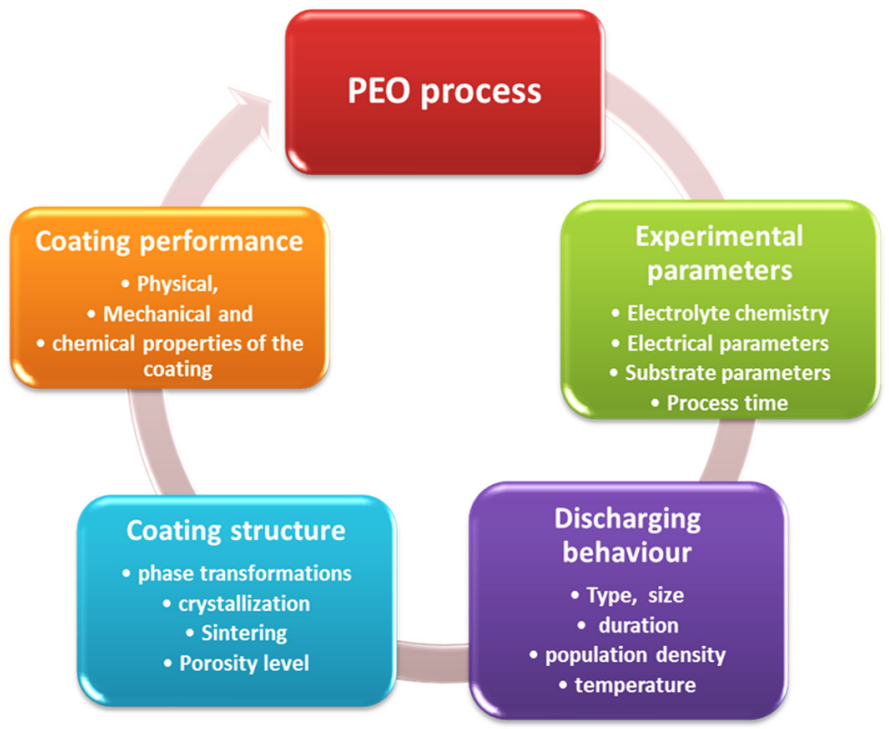

Figure 11: Relationships between PEO processing parameters, discharge behaviour, coating structure and performance. 
The main conclusions are:

- $\quad$ The PEO processing of light alloys is strongly influenced by such parameters as electrolyte composition and concentration, current or voltage applied and substrate alloy.

- Generally, these parameters have a direct influence on the discharging behavior: type, size, duration, population density and temperature.

- $\quad$ The discharges play an essential role in the formation, relative thickness and resulting composition of the 3-layer oxide structure, by influencing phase transformations, crystallization and sintering.

- This, then, affects the physical, mechanical and chemical properties of the coating.

- The corrosion performance is more closely related to the protective nature of the dense oxide layer at the coating-substrate interface.

- The wear performance is effected mainly by intermediate layer. Since the coating is integral with the substrate, there is good adhesion.

\section{Recommendations for production of high quality coatings}

Tables 4-6 summarise the process parameters effects on the coating quality and makes recommendations for the production of high quality coatings.

Table 4: $\quad$ The effect of current density and current mode on the coatings.

\begin{tabular}{|c|c|l|}
\hline Process parameter & "Value" & \multicolumn{1}{|c|}{ Effect on Coating } \\
\hline \multirow{3}{*}{ Current Density } & low & Low growth rate; more compact \\
\cline { 2 - 3 } Current Mode & high & High growth rate; less compact \\
\cline { 2 - 3 } & Unipolar $(\mathrm{U})$ & Higher growth rate; less compact \\
\cline { 2 - 3 } & Bipolar $(\mathrm{B})$ & Low growth rate; more compact \\
\cline { 2 - 3 } & Hybrid (B+U) & Intermediate growth rate; less compact \\
\cline { 2 - 3 } & Hybrid (U+B) & Intermediate growth rate; more compact \\
\hline
\end{tabular}

Recommendation: Intermediate current density + Bipolar Mode = best coatings.

Table 5: The effect of the substrate composition on the coatings.

\begin{tabular}{|l|l|l|}
\hline Substrate & Composition & $\begin{array}{l}\text { Elements from substrate can incorporated into } \\
\text { coating. Generally for Mg-alloys, the growth rate of } \\
\text { the coating after initial processing period is } \\
\text { independent of alloy composition. }\end{array}$ \\
\hline
\end{tabular}

Recommendation: PEO coating is applicable to all lightweight alloys regardless of their composition. However, the growth rate and phase composition/porosity of coatings is composition dependent. 
Table 6: The effect of the electrolyte chemistry on the coatings.

\begin{tabular}{|l|l|l|}
\hline Electrolyte & Concentration & $\begin{array}{l}\text { Higher concentration increases conductivity, decreases } \\
\text { breakdown voltage, thereby increasing growth rate. }\end{array}$ \\
\cline { 2 - 3 } & Composition & $\begin{array}{l}\text { Addition of aluminate and silicate can induce formation } \\
\text { of spinels in coating. Higher hardness, better wear } \\
\text { properties, and improved corrosion resistance. } \\
\text { Tungstate addition can provide inhibitive effect and } \\
\text { improved corrosion resistance. }\end{array}$ \\
\hline
\end{tabular}

Recommendation: tailor the electrolyte to produce coating with desired phases/properties.

\section{References}

[1] Yerokhin AL, Nie X, Leyland A, Matthews A and Dowey SJ, Plasma electrolysis for surface engineering. Surface \& Coatings Technology, 122, pp. 73-93, 1999.

[2] Hussein RO, Zhang P, Northwood DO and Nie X, Improving the Corrosion Resistance of Magnesium Alloy AJ62 by a Plasma Electrolytic Oxidation (PEO) Coating Process. Corrosion and Materials, 36 (3), pp. 38-49, 2011.

[3] Hussein RO, Nie X, Northwood DO, Yerokhin A, Matthews A, Spectroscopic study of electrolytic plasma and discharging behaviour during the plasma electrolytic oxidation (PEO) process. Journal of Physics D: Applied Physics, $\mathbf{4 3}$ pp. 105203, 2010.

[4] Dunleavy CS, Golosnoy IO, Curran JA, Clyne TW, Characterisation of discharge events during plasma electrolytic oxidation. Surface \& Coatings Technology, 203, pp. 3410-3419, 2009.

[5] Hussein RO, Nie X and Northwood DO, The Application of Plasma Electrolytic Oxidation (PEO) to the Production of Corrosion Resistant Coatings on Magnesium Alloys: a Review, Corrosion and Materials, 38 (1), pp. 53-63, 2013.

[6] Hussein RO and Northwood DO, Improving the performance of magnesium alloys for automotive applications, WIT Transactions on the Built Environment,137, pp. 531-544, 2014.

[7] Hussein RO, Nie X and Northwood DO, Plasma electrolytic oxidation (PEO) coatings on $\mathrm{Mg}$-alloys for improved wear and corrosion resistance, WIT Transactions on Engineering Sciences, 91, pp. 163-176, 2015.

[8] Hussein RO, Nie X and Northwood DO, A spectroscopic and microstructural study of oxide coatings produced on a Ti-6Al-4V alloy by Plasma Electrolytic Oxidation, J. of Materials Chemistry and Physics, 134 (1), pp. 484-492, 2012.

[9] Northwood DO, Hussein RO and Nie X, Environmentally Friendly Surface Treatment of Light Alloy Materials for Automotive Applications. The 18th International Corrosion Congress, Perth, Australia 2011, 2, pp. 825-836. 2011.

[10] Liang J, Bala Srinivasan JP, Blawert C, Störmer M, Dietzel W, Electrochemical corrosion behaviour of plasma electrolytic oxidation 
coatings on AM50 magnesium alloy formed in silicate and phosphate based electrolytes. Electrochimica Acta, 54, pp. 3842-3850, 2009.

[11] Cakmat E, Tekin KC, Malsyooglu U and Shrestha S, The effect of substrate composition on the electrochemical and mechanical properties of PEO coatings on Mg alloys. Surface \& Coatings Technology, 204, pp. 1305$1313,2010$.

[12] Wei CB, Tian XB, Yang SQ, Wang XB, Fu RKY, Chu PK, Anode current effects in plasma electrolytic oxidation. Surface \& Coatings Technology, 201, pp. 5021-5024, 2007.

[13] Hussein RO, Northwood DO, Su JF, Nie X, A study of the interactive effects of hybrid current modes on the tribological properties of a PEO (plasma electrolytic oxidation) coated AM60B Mg-alloy. Surface \& Coatings Technology, 215, pp. 421-430, 2013.

[14] Qiu Z, Wang R, Zhang Y, Qu Y, Wu X, Study of Coating Growth Behavior During the Plasma Electrolytic Oxidation of Magnesium Alloy ZK60, Journal of Materials Engineering and Performance, 24, pp. 1483-1491, 2015.

[15] Hussein RO, Nie X, Northwood DO, An investigation of ceramic coating growth mechanisms in plasma electrolytic oxidation (PEO) processing. Electrochimica Acta 112, pp. 111-119, 2013.

[16] Hussein RO, Nie X and Northwood DO, Influence of process parameters on electrolytic plasma discharging behavior and aluminum oxide coating microstructure. Surface \& Coatings Technology, 205, pp. 1659-1667, 2010.

[17] Hussein RO, Nie X and Northwood DO, Coating growth behaviour during the plasma electrolytic oxidation process. The Journal of Vacuum Science and Technology A, 28, pp. 766-773, 2010.

[18] Hussein RO and Northwood DO, Production of anti-corrosion coatings on light alloys (Al, Mg, Ti) by Plasma Electrolytic Oxidation (PEO, 'In: Developments in Corrosion Protection, (M. Aliofkhazraei, Ed.) InTech Open Publishers, ISBN 980-953-307-1100-2. 2013.

[19] Duan H, Yan C, Wang F, Effect of electrolyte additives on performance of plasma electrolytic oxidation films formed on magnesium alloy AZ91D, Electrochimica Acta, 52, pp. 3785-3793, 2007.

[20] Curran JA and Clyne WT, Thermo-physical properties of plasma electrolytic oxide coatings on aluminum. Surface \& Coatings Technology, 199, pp. 177-183, 2005.

[21] Yerokhin AL, Leyland A, Matthews A, Kinetic aspects of aluminium titanate layer formation on titanium alloys by plasma electrolytic oxidation. Applied. Surface. Science, 200, pp. 172-184, 2002.

[22] Hussein RO, Northwood DO and Nie X, Processing-Microstructure Relationships in the Plasma Electrolytic Oxidation (PEO) Coating of a Magnesium Alloy, Materials Sciences and Applications (MSA), 5 (3), pp. 124-139, 2014.

[23] Hussein RO, Nie X and Northwood DO, Effect of cathodic current density on the corrosion protection of the oxide coatings formed on AZ91D 
454 High Performance and Optimum Design of Structures and Materials II

magnesium alloy by plasma electrolytic oxidation. Corrosion and Prevention", Australia paper no. 112, 2013.

[24] Hussein RO, Northwood DO, Su, JF and Nie X, A study of the interactive effects of hybrid current modes on the tribological properties of a PEO (plasma electrolytic oxidation) coated AM60B Mg-alloy, Surface \& Coatings Technology, 215, pp. 421-430, 2013.

[25] Hussein RO, Northwood DO and Nie X, The effect of processing parameters and substrate composition on the corrosion resistance of plasma electrolytic oxidation (PEO) coated magnesium alloys, Surface \& Coatings Technology, 237, pp. 357-368, 2013.

[26] Shrestha S, Magnesium and Surface Engineering-Technology Vision. Editorial in Surface Engineering, 26, pp. 313-316, 2010.

[27] Hussein RO, Nie X and Northwood D.O, The roles of the electrolyte composition and concentration on the corrosion resistance of the oxide coatings formed on AZ91D magnesium alloy by plasma electrolytic oxidation, Corrosion and Prevention; Australia 2014; Code 109535, 2014. 